V.V. Vasilevskij

\title{
DYNAMICS MODEL OF MOISTURE IN PAPER INSULATION-TRANSFORMER OIL SYSTEM IN NON-STATIONARY THERMAL MODES OF THE POWER TRANSFORMER
}

Introduction. An important problem in power transformers resource prognosis is the formation of moisture dynamics trends of transformer insulation. Purpose. Increasing the accuracy of power transformer insulation resource assessment based on accounting of moisture dynamics in interrelation with temperature dynamics. Working out of moisture dynamics model in paper insulation-transformer oil system in conjunction with thermodynamic model, load model and technical maintenance model. Methodology. The mathematical models used for describe the moisture dynamics are grounded on nonlinear differential equations. Interrelation moisture dynamics model with thermodynamic, load and technical maintenance models described by UML model. For confirming the adequacy of model used computer simulation. Results. We have implemented the model of moisture dynamics in power transformers insulation in interrelation with other models, which describe the state of power transformer in operation. The proposed model allows us to form detailed trends of moisture dynamics in power transformers insulation basing on monitoring data or power transformers operational factors simulation results. We have performed computer simulation of moisture exchange processes and calculation of transformer insulation resource for different moisture trends. Originality. The offered model takes into account moisture dynamics in power transformers insulation under the influence of changes of the power transformers thermal mode and operational factors. Practical value. The offered model can be used in power transformers monitoring systems for automation of resource assessment of oil-immersed power transformers paper insulation at different phase of lifecycle. Model also can be used for assessment of projected economic efficiency of power transformers exploitation in projected operating conditions. References 7, figures 4.

Key words: oil-paper insulation, power transformer, computer model, moisture dynamics.

С целью повыщения точности расчета ресурсных характеристик силового трансформатора предложена модель прогнозирования динамики влажности бумажно-масляной изоляции. Предложенная модель отличается от существуюциих учетом процессов миграции влаги в бумажно-масляной изоляции под влиянием изменения теплового режима силового трансформатора. Проведено компьютерное моделирование износа бумажно-масляной изоляции и произведена оценка влияния возможного изменения степени увлажненности на ресурс. Библ. 7, рис. 4 .

Ключевые слова: бумажно-масляная изоляция, силовой трансформатор, компьютерное моделирование, динамика влажности.

Introduction. Establish of monitoring systems for transformer equipment is actual scientific and technical task. A number of systems, such as domestic manufacturers (LLC «Energoavtomatizatsiya», JSC «ZTR» [1]), and foreign (ABB, Siemens) [2], one of the functions of which is the possibility of residual life assessment unit of the power transformer (PT) based on monitoring data are known.

Life of oil-filled power transformer is mainly determined by resource of its paper insulation (PI). Effect on consumption of resource of the PI PT the following factors: the change in temperature, the degree of hydration of cellulose and transformer oils (TO), and the degree of oxidation of the oil. Water may be produced during operation in the PT as a product PI aging, and exposed from the environment due to the partial depressurization tank. The migration of moisture in the insulation system is influenced by changes in the thermal regime $\mathrm{PT}$.

An important problem in the calculation of the projected resource characteristics in operation is the construction PT possible humidity trends paper-oil insulation (POI), TO and acidity changes in operating factors such as ambient temperature and load current.

Analysis of investigations. The existing models of moisture exchange are defined by their purpose determining moisture of PI based on TO moisture measurement in monitoring the use of PT with equilibrium moisture content curves [3] or computational methods [4]. In such models do not take into account (or not sufficiently taken into account), possible change of operation factors in the forecast horizon.

It is also possible to form the trend humidity PI based on the assumption that the moisture content of the growth of POI of PT due to aging would be approximately 2-3\% [5] and that this growth will occur linearly during operation.

In this case the reduced rate forecast accuracy PT resource, there is no opportunity to get a complete picture of the dynamics of moisture and to evaluate its impact on resource consumption.

At this stage there are no models by which to predict the dynamics of moisture in the insulation system based on PT dynamics operating factors, maintenance (M) parameters.

Problem definition. The purpose of research is to improve the accuracy of calculation of lifetime characteristics of POI of PT by taking into account the dynamics of moisture in conjunction with the temperature dynamics of the PI and maintenance in resource consumption model. To achieve this goal it is necessary to solve the following tasks:

- to propose ways to assess the impact of moisture migration in POI PT to the resource PI PT;

- to build a model of the dynamics of the POI of humidity in the moisture content in the non-equilibrium state, in cooperation with the POI model load, ambient temperature, and maintenance of PT; 
- to conduct computer simulations of POI resource consumption in order to assess the impact of migration of moisture on the resource consumption POI.

Results of investigations. Block diagram of the relationship model of moisture exchange in POI PT with other elements of the model predictive resource consumption is shown in Fig. 1. It includes a model of the external operating factors (OF, it forms loads $I_{d}$ and coolant temperature $\theta_{a}$ current trends), a model of technical condition and maintenance of the POI (POI TC and M, forming the heat capacity and thermal resistance of the trends for different types of cooling $R_{O N} ; R_{O F} ; C_{O N} ; C_{O F F}$ ), a thermodynamic model (TDM, generates temperature trend most heated point (TMHP), $\theta_{h}$ ), moisture exchange model in POI PT and wear evaluation unit (WE, the calculation of the resources expended $L$ ) [6].

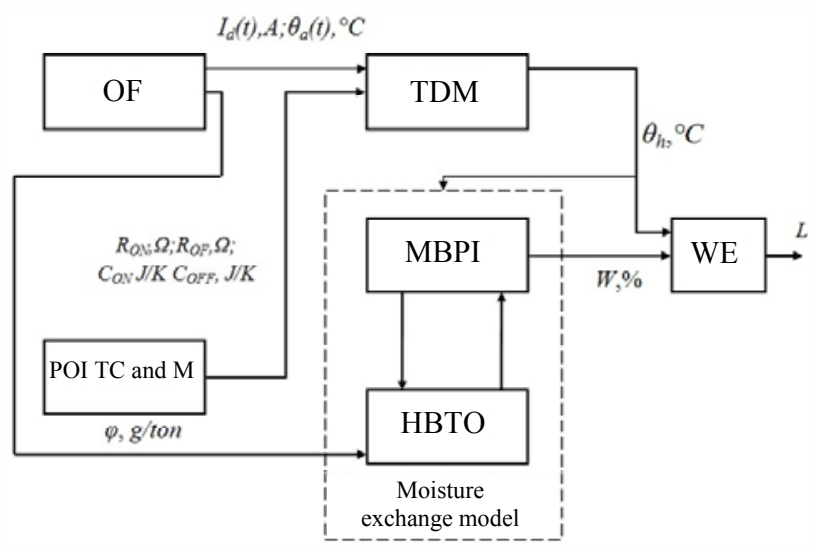

Fig. 1. Block diagram of the relationship of moisture exchange model with other models

A moisture exchange model, in turn, consists of a moisture block of PI (MBPI) and humidity of TO block (HBTO) which are interconnected. by $[5]$ :

Calculated PI humidity at certain time $t$ is given

$$
W_{c}=A \cdot e^{-B \cdot \Theta_{h}} \cdot p^{k+a \cdot \Theta_{h}},
$$

where $W_{c}$ is the calculated PI humidity, \%; $A, B, k, a$ are the table data for certain type of insulation; $\theta_{h}$ is the TMHP, ${ }^{\circ} \mathrm{C} ; p$ is the partial water vapor pressure, mmHg.

Dynamics humidity of PI TO system is described using UML model shown in Fig. 2.

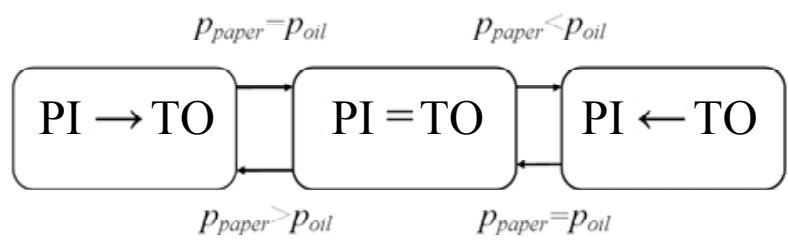

Рис. 2. Moisture exchange model in the system PI TO

Model is a diagram of states, transitions between which are carried out taking into account the relationship between the partial pressure of water vapor in the PI ( $p_{p a-}$ $\left.{ }_{p e r}\right)$ and TO $\left(p_{o i l}\right)$. In each state, the appropriate action is carried out:
1) $\mathrm{PI} \rightarrow \mathrm{TO}$ - humidity transfer from PI to TO. The amount of moisture that migrates from PI to TO during time $d t$ at change of the TMHP value is determined by the differential equation:

$$
\frac{d W_{\text {paper }}}{d t}=\frac{W_{\text {c.paper }\left(\Theta_{h 1}\right)}-W_{\text {paper }\left(\Theta_{h 2}\right)}}{\tau},
$$

where $\tau$ is the moisture transfer time constant; $W_{\text {c.paper }\left(\Theta_{h 1}\right)}$ is the PI humidity $W_{c}$ at TMHP $\theta_{h 1}, \%$; $W_{c \text { paper }\left(\Theta_{h 2}\right)}$ is the PI humidity $W_{c}$ at TMHP $\theta_{h 2}, \%$.

Change of TO degree of moisture as a result of the migration of moisture from PI:

$$
\frac{d W_{\text {oil }}}{d t}=\frac{W_{\text {c.oil }\left(\Theta_{h 1}\right)}+\frac{W_{\text {paper }} \cdot m_{\text {oil }}}{m_{\text {paper }}}}{\tau},
$$

where $W_{\text {c.oil }\left(\Theta_{h 1}\right)}$ is the TO humidity at TMHP $\theta_{1}, \% ; m_{\text {oil }}$ is the total mass of TO in the PT, $\mathrm{t}$; $m_{\text {paper }}$ is the total mass of the PI in the PT, $t$.

Value of TO humidity at TMHP $\theta_{h 1}$ is determined either on the monitoring results, or the results of peer review.

2) $\mathrm{PI} \leftarrow \mathrm{TO}$ - humidity transfer from TO to PI. The amount of moisture that migrates from TO to PI during time $d t$ is characterized by TMHP change:

$$
\frac{d W_{\text {paper }}}{d t}=\frac{W_{\text {c.paper }\left(\Theta_{h 2}\right)}-W_{\text {paper }\left(\Theta_{h 1}\right)}}{\tau} .
$$

Changing the degree of hydration of TO as a result of the humidity migration to PI in this case:

$$
\frac{d W_{\text {oil }}}{d t}=\frac{W_{\text {c.oil }\left(\Theta_{h 1}\right)}-\frac{W_{\text {paper }} \cdot m_{\text {oil }}}{m_{\text {paper }}}}{\tau} .
$$

3) $\mathrm{PI}=\mathrm{TO}-$ equilibrium state, to which the system tends at equality temperatures PI, TO and the cooling medium.

In all states in the operation phase occurs moisture increase in the PI and TO, the dynamics of the increase described by the following differential equations:

$$
\frac{d m_{\text {oil }}}{d t}=k_{\text {oil }}, \frac{d m_{\text {paper }}}{d t}=k_{\text {paper }},
$$

where $k_{\text {oil }}, k_{\text {paper }}$ are the coefficients which characterize the increase in mass of the moisture in TO and PI, respectively, $\mathrm{g} / \mathrm{kg} \cdot \mathrm{h} ; m_{\text {oil }}, m_{\text {paper }}$ is the moisture mass in TO TM and PI, respectively, $\mathrm{kg}$.

The initial state is the state PI = TO, in which the system is for a period of time $d t$ until the equality of the partial pressure of water vapor in the POI PT. The initial data for the model are moisture exchange values TMHP measured relative humidity of transformer oil, the oil temperature near the humidity sensor, the content of aromatic hydrocarbons in the oil and table data for certain types of insulation. The equilibrium value of PI humidity is determined by (1) $\theta_{h 1}$ and relative humidity TO $\varphi(\%)$, the value of $\varphi$ is determined according to TO or monitoring by experts. Moisture gain in POI PT due to the aging of cellulose or depressurization tank PT is calculated using the formula (6). 
When you change the temperature PT is a violation of the balance of the partial pressures and the system goes into a state of $\mathrm{PI} \rightarrow \mathrm{TO}\left(p_{\text {paper }}>p_{\text {oil }}\right)$ or in the state of $\mathrm{PI} \leftarrow \mathrm{TO}\left(p_{\text {paper }}>p_{\text {oil }}\right)$. Dynamics of humidity changes in PI and TO due partial pressure and humidity gradients within the time period $d t$ is calculated by the formulas (2-5).

Sources of raw data to calculate the moisture exchange is the data model of external operational factors (moisture value growth as a result of decomposition of cellulose and water revenues from the environment), the technical condition of the POI model (changes in baseline), a thermodynamic model (TMHP). The resulting paper insulation moisture value is used in calculating the resource in the resource evaluation unit.

Then the model of $\mathrm{M}$ provides for both routine $\mathrm{M}$ and $\mathrm{M}$ by technical condition. Result of $\mathrm{M}$ of PT is to reduce the humidity and PI TO acidity to certain minimum values. When working on the model variant planned M lowering humidity indicators and acidity POI PT occurs at predetermined periods of time (by drying and regeneration POI PT). In the case of condition based $\mathrm{M}$ decrease in humidity and acidity indicators POI PT occurs upon reaching these parameters critical values.

In the proposed model allowed the following simplifications:

- the process of $\mathrm{M}$ is accepted as the CT process with zero duration;

- simulation does not include changes in resource characteristics PI PT in the time period from the moment of installation of PT on site prior to its inclusion under the load;

- increase the degree of oil oxidation occurs linearly over the period of operation between the two M.

As the base used for the trend test the adequacy of the model obtained from the results may be accepted PT trend resource flow with the same parameters, the monitoring system equipped and located in similar environments.

To set up a model of moisture exchange used or curves of Oommen or Fabr and Piccioni [7] for the equilibrium moisture content in a system PI - TO. It is expected that before turning on the PT under the load as a result of the thermodynamic processes in the system temperature POI PT - environment called and will be equal to $\theta_{a}$. In accordance with the law of equilibrium [5], the partial pressure of water vapor in the system is also equalized. To set the initial conditions of simulation $\theta \mathrm{h}$ assumed constant and equal $\theta_{a}$, TO is equal to the absolute humidity of $10-15 \mathrm{~g} / \mathrm{m}$ (which corresponds to the TO PT humidity class I [5]). Next is $W_{c}$ calculation for given initial conditions and the resulting humidity value of PI is compared with a reference point on the curves of Oommen or Fabr and Piccioni and to validate the calculation. The resulting value will be the value of $W_{c} \mathrm{PI}$ humidity at the beginning of operation of PT.

Proposed models are implemented in the program Matlab Simulink. As an example of simulation model to assess POI performance deterioration held for two variants of the system dynamics humidity PI - TO.
In the first variant, moisture value during the simulation and decreases linearly increases up to a certain initial value after M of PT (Fig. 3, curve $a$ ). In the second embodiment applied humidity trend obtained by using the proposed model (Fig. 3, curve $b$ ).

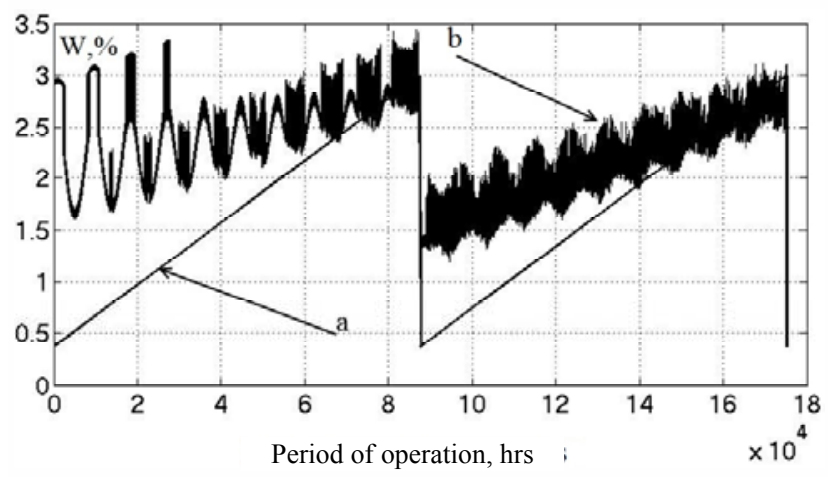

Fig. 3. POI humidity trends

Initial data for OF models, the TC POI and $\mathrm{M}$ and TDM and rated current of the transformer is equal to 406 A, output no-load losses is equal to $29.3 \mathrm{~kW}$, the maximum acidity TO equals $0.29 \mathrm{mg} \mathrm{KOH} / \mathrm{g}$, the base value of acidity TO $0.2 \mathrm{mg} \mathrm{KOH} / \mathrm{g}$, the average annual ambient temperature is $9.4{ }^{\circ} \mathrm{C}$, the amplitude of the annual change in the average daily temperature $\theta_{a}$ equal to 12.6 ${ }^{0} \mathrm{C}$, the amplitude of the diurnal changes $\theta_{a}$ equal to $4{ }^{0} \mathrm{C}$, the average annual rate of change $\theta_{a}$ is $2{ }^{0} \mathrm{C}$, the rate of change Id average $2 \mathrm{~A}$, the average daily change $I_{d} 20 \mathrm{~A}$, the average annual change $I_{d} 20 \mathrm{~A}, I_{d}=244.2 \mathrm{~A}$ maximum value TMHP taken equal to $150{ }^{0} \mathrm{C}$, the maximum value of the moisture content of the paper insulation $-5 \%$.

Initial data for trending humidity Fig. 3, curve $a$ : base value is equal to the moisture content of PI $0.37 \%$, the maximum moisture content of $3 \%$ PI.

Initial data for trending humidity Fig. 3, curve $b$ : the content of aromatic hydrocarbons in oil $C_{A}=17 \%$ (oil T-750 GOST 982-80), $A=5.55, B=0.034, k=0.49$, $a=-0.0007$ (cardboard electrotechnical ЭМЦ).

Simulation period -20 years. The simulation results under the above defined raw data shown in Fig. 4. The $x$-axis represents the life of PT in hours, and the vertical axis - the value of the consumed resources of $L$, as in hours.

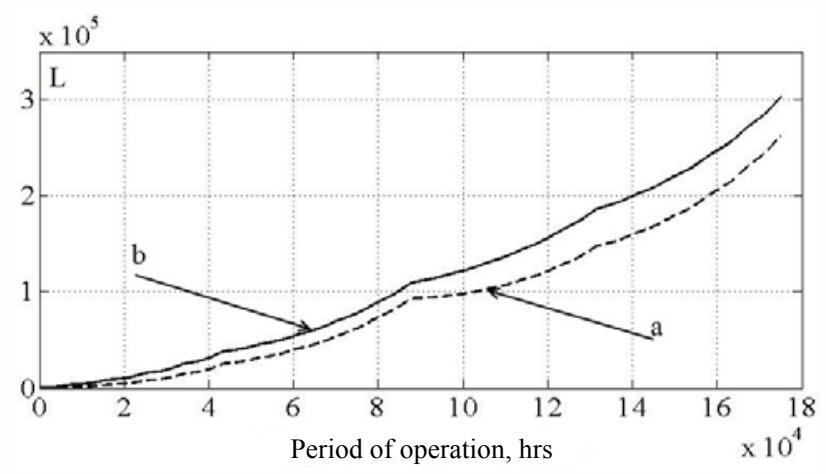

Fig. 4. Results of simulation 
From obtained results it is seen that the use of different versions of humidity PI trend has a significant effect on the final value of the consumed resource. So, wear of the PT when the trend Fig. 3, it was 30.03 years and 20 years of operation in the case of Fig. $3, b$ -34.6 years.

\section{Conclusions.}

A model of moisture exchange in the system of «paper insulation - transformer oil» in conjunction with the other models, which describe the state of the power transformer in operation is proposed: a model of operation factors, the thermodynamic model of a power transformer model and the technical condition of paper-oil insulation.

The proposed model allows you to build a detailed trend dynamics humidity paper-oil insulation according to the monitoring unit power transformer or on the results of the simulation changes operational parameters of the power transformer.

Given the dynamics of moisture content of paper-oil insulation of a power transformer can improve the accuracy of estimation of the resource of paper insulation.

\section{REFERENCES}

1. E'kspertnaya sistema monitoringa, diagnostiki i upravleniya transformatornym oborudovaniem «E'SMDU TRANS» proizvodstva $P A O$ «ZTR» (Expert system for monitoring, diagnostic and control of transformer equipment «E'SMDU TRANS» produced by PAO «ZTR») Available at: http://www.ztr.com.ua/ru/monitoring-system. (accessed 13 May 2014). (Rus).

2. Rusov, V.A., Ovsyannikov, A.G., Zhivodernikov S.V. Foreign experience of oil-filled equipments monitoring. Materialy IV nauchno-prakticheskogo seminara Obshchestvennogo soveta spetsialistov Sibiri i Vostoka po problemam monitoringa trans- formatornogo oborudovaniya $i$ diagnostiki elektricheskikh ustanovok [Proceedings of the IV scientific workshop of the Public Council of experts of Siberia and the East on the monitoring of transformer equipment and diagnostics of electrical installations]. Novosibirsk, Russia, 20-24 April 2009, pp. 7-22. (Rus). 3. Cheng J., Robalino D., Werelius P., Ohlen M. Advanced technique for moisture condition assessment in power transformers. Journal of International Council on Electrical Engineering, 2014, vol.4, no.3, pp. 185-191. doi: 10.5370/JICEE.2014.4.3.185.

4. Mordkovich A.G. The system of management, monitoring and diagnostics of transformers SUMTO. ELEKTRO. Elektrotekhnika, elektroenergetika, elektrotekhnicheskaia promyshlennost' - ELEKTRO. Electrical engineering, power industry, electrical industry, 2007, no.6, pp. 23-28. (Rus).

5. Lizunov S.D., Lokhanin A.K. Silovye transformatory. Spravochnaia kniga [Power transformers. Handbook]. Moscow, Energoizdat Publ., 2004. 616 p. (Rus).

6. Polyakov M.A., Vasilevskij V.V. Prediction of wearing out of power transformer winding insulation. Tekhnichna elektrodynamika - Technical electrodynamics, 2014, no.5, pp. 65-67.

7. Du Y., Zahn M., Lesieutre B.C., Mamishev A.V., Lindgren S.R. Moisture equilibrium in transformer paper-oil systems. IEEE Electrical Insulation Magazine, 1999, vol.15, no.1, pp. 1120. doi: $\mathbf{1 0 . 1 1 0 9 / 5 7 . 7 4 4 5 8 5 . ~}$

Received 04.02.2016

V.V. Vasilevskij, Postgraduate Student,

Zaporozhye National Technical University, 64, Zhukovsky Str., Zaporozhye, 69063, Ukraine, phone+380508893073, e-mail: Lisses@ukr.net

How to cite this article:

Vasilevskij V.V. Dynamics model of moisture in paper insulation-transformer oil system in non-stationary thermal modes of the power transformer. Electrical engineering \& electromechanics, 2016, no.3, pp. 17-20. doi: 10.20998/2074-272X.2016.3.02. 